\title{
Preface to Issue 24/2, May 2021
}

\author{
András Szigeti ${ }^{1,2}$
}

Accepted: 18 May 2021/ Published online: 25 May 2021

(C) The Author(s), under exclusive licence to Springer Nature B.V. 2021

There is a common thread running through most of the articles in this issue: the relevance of empirical research to ethical theorizing. As everything in philosophy, such a methodological approach can be challenged too. You don't even have to deny that social, psychological, anthropological, and historical studies of moral practices can be instructive in themselves to think that empirical findings from such studies might be difficult to incorporate into conceptual analyses and armchair reflections. There is too much noise, too much contingency, too much variety "out there", one might think, for the study of actual practices to yield anything of lasting significance for ethics as a theoretical discipline. And even setting these problems aside, familiar categorical worries about the fact-value gap will of course always loom large.

Needless to say, neither we nor the authors of articles in this issue presume to have laid these concerns to rest. However, the insightful and innovative contributions assembled here do appear to demonstrate that there are many topics where ethical theory most definitely profits from a close study of moral practices, and conversely too, that empirical investigations can be helpfully structured and interpreted using the concepts of normative ethics and metaethics. So, in their "Virtue of Self-Compassion" Simon Keller and Felicia A. Huppert draw on psychological research to show that self-compassion leads to improved well-being and functioning, and then go on to build on this basis a novel theory of self-compassion. This theory highlights the ways in which the ethical relationship with self is more complicated than many philosophical treatments until now would have had us believe. At the same time, Keller and Huppert are also critical of how self-compassion is defined in the psychological literature, and what enables them to mount such a critique is precisely the fact that they tap into theoretical insights of virtue ethics. This paper thus shares affinities with both the topic and the approach of Hannah Read's "Empathy and Common Ground". Against some recent critics, Read defends empathy arguing on the basis of both conceptual and empirical considerations that empathy is an important capacity for moral practice as it helps people disagreeing or divided to find common ground.

András Szigeti

andras.szigeti@liu.se

1 Lund Gothenburg Responsibility Project (LGRP), Lund University, Lund, Sweden

2 Philosophy Division, Institute for Culture and Society (IKOS), Linköping University, Linköping, Sweden 
Explicitly drawing on research in experimental philosophy Matthew Rachar's "QuasiPsychologism about Collective Intention" takes on today's arguably most influential theoretical account of what it is for people to act together, namely the account according to which joint agency is constituted by appropriately combined intentions of participating agents. Interestingly, Rachar does not think that this account should be rejected. His aim rather is to show that when properly interpreted certain experimental results can be used to improve it. It is noteworthy that Nir Ben-Moshe's "A Defense of Modest Ideal Observer Theory" also marries conceptual analysis with careful attention to actual moral practices in order to develop an ideal observer theory. While the paper takes Adam Smith's account of the impartial spectator as its point of departure, Ben-Moshe constructs the hypothetical conditions that ground normative authority from the "psychology and interactions of actual human beings".

For another conversation firmly rooted in empirical psychological research, we also have an exciting book symposium, including replies by the author, on Matt Stichter's recent book The Skillfulness of Virtue (2018). The book and the contributions to the symposium are devoted to the "skill model" of virtue. Relying on psychological research on self-regulation and practical expertise, Stichter argues that virtues, including epistemic virtues, are in fact a special kind of practical skill. Some of the pieces in this collection are critical, while some look for ways to expand the model, but all seem to agree with Noell Birondo's assessment in the introduction to the symposium that Stichter's book does not only make a major contribution to virtue theory but might have a recognizable impact on research in empirical psychology and beyond.

In yet another take on the relationship between theory and practice, Frauke Albersmeier's "Speciesism and Speciescentrism" considers the relationship of empirical descriptions and normative evaluations in the context of the debate on "speciesism". As is well known, the term "speciesism" was originally introduced in order to condemn discrimination against nonhuman animals. However, Albersmeier notes that "speciesism" is often used descriptively as a purely technical term too. She argues that once the normative and descriptive concepts are properly distinguished, we can reject attempts to redefine speciesism as a stance that is by definition morally unobjectionable, and we can do so for the same reason attempts to redefine racism and sexism in this way should be rejected.

The last two articles to be mentioned in this roll call have a more straightforwardly theoretical focus. That said, the conclusions of both pieces could impact on our understanding of existing moral practices and could have seriously implications for the justifiability of certain assumptions underlying them. Peter Schaber in his "The Reason-Giving Force of Request" asks how exactly making requests generates valid reasons for action. He argues that requests create reasons if and only if doing so is valuable for the requester, and if they respect the requestee. The normative power we have to make requests is of instrumental value because it has the potential for creating and shaping valuable interactions and relationships for the requester and the requestee. Finally, Fumitake Yoshizawa's "A Dilemma for Benatar's Asymmetry Argument" challenges Benatar's celebrated defense of anti-natalism. Specifically, Yoshizawa takes issue with one of the key arguments put forward in favor of natalism, and he challenges the asymmetry argument in a different way than other philosophers have done before. Some aspects of this controversy are certainly technical. Nevertheless, this debate could change how we think about harm and benefit as well as the (dis)value of being alive. 
Last but not least, don't forget to take a look at our book reviews. These too focus on newly-published monographies and collections dealing with various aspects of the relation between ethical theory and moral practice. We hope you will enjoy this issue. As always, we look forward not just to your comments and criticisms, but if working from the home office has made you productive your latest manuscripts as well.

Publisher's Note Springer Nature remains neutral with regard to jurisdictional claims in published maps and institutional affiliations. 